\title{
Canine trypanosomiasis in an endemic Costa Rican community: Demonstration of the active infection cycle
}

\author{
Marta C. Bonilla ${ }^{\mathrm{a}, *}$, Ruth M. Castro-Vásquez ${ }^{\mathrm{a}}$, Marco Vinicio Herrero-Acosta ${ }^{\mathrm{a}}$, \\ Andrea Urbina-Villalobos ${ }^{\mathrm{b}}$, Gaby Dolz ${ }^{\mathrm{a}}$ \\ ${ }^{a}$ Laboratorio de Docencia e Investigación en Medicina Poblacional, Programa MEDPOB, Escuela de Medicina Veterinaria, Universidad Nacional de Costa Rica. Heredia, \\ Costa Rica \\ ${ }^{\mathrm{b}}$ Laboratorio de Zoonosis, Escuela de Medicina Veterinaria, Universidad Nacional de Costa Rica, Heredia, Costa Rica
}

\section{A R T I C L E I N F O}

\section{Keywords:}

Canine trypanosomiasis

Serology

PCR

Sequencing

\begin{abstract}
A B S T R A C T
A cross-sectional study was conducted to determine the prevalence of canine trypanosomiasis in an endemic community of Costa Rica. The indirect hemagglutination and indirect immunofluorescence assay yielded positive results in $6.4 \%(20 / 314)$ of canine samples analyzed; polymerase chain reaction (PCR) and light microscopy yielded positive results in one dog. Subsequently, a longitudinal study was carried out with 55 negative $T$. cruzi canines in the cross-sectional study. These dogs were divided into two groups: Group 1, which consisted of 25 individuals that lived in dwellings where triatomines were found in their homes; and Group 2, which consisted of 30 dogs that lived in dwellings where triatomines were not found during the previous study in their homes. Seroconversion occurred in six dogs (10.9\%) in Group 1 in the first months of the year (dry season); these dogs remained seropositive until the end of the study. Only one of the six seropositive canines was also found positive once in T. cruzi PCR. The analysis of the amplified T. cruzi sequences of dogs and triatomines showed that all of them belonged to the TcI lineage. It is recommended that residents be made aware of the need to eliminate vectors in their homes and their surroundings.
\end{abstract}

\section{Introduction}

Chagas disease or American trypanosomiasis is a zoonotic disease caused by the protozoan Trypanosoma cruzi, which can infect humans as well as domestic and wild animals (Galvao and Justi, 2015). This parasite is transmitted by triatomine vectors of the order Hemiptera, family Reduviidae, and subfamily Triatominae. They are hematophagous and primarily nocturnal insects that feed on the blood of humans, and of wild and domestic animals (Zeledón et al., 2016). Chagas disease occurs primarily in Latin America, where it is endemic. In endemic countries it is recommended to routinely evaluate dogs, which are one of the principal domestic hosts. Under natural conditions dogs are infected more frequently than humans, making it possible to use them as sentinels to estimate the risk of infection in humans (Abad-Franch et al., 2010; Barbabosa-Pliego et al., 2011; Greene, 2012; Castillo-Neyra et al., 2015).

Until 2002, Chagas disease was not considered to be a public health priority in Costa Rica. Now, however, reporting the disease in humans is mandatory, and passive epidemiological surveillance is carried out, as specified in the Standard for the Comprehensive Care of Chagas
Disease (Government of Costa Rica, 2012). However, it is not compulsory to report the disease in animals, and there are no epidemiological surveillance programs in canines in Costa Rica (Ministry of Agriculture and Livestock, 2008).

Canine trypanosomiasis was reported for the first time in Costa Rica in 1952 in a dog in San Rafael de Heredia, when the parasite was detected in a blood smear (Berrocal-Avila et al., 1993). The dog was living with a family that was also infected with the parasite. In 1993 another case of acute trypanosomiasis was reported in San Rafael de Heredia in a 9-month-old puppy that died suddenly. Cardiac lesions compatible with $T$. cruzi were found during necropsy and histopathology; it was, therefore, determined to be the cause of death. Vectors infected with the parasite also were found in the dwelling in which this puppy lived (Berrocal-Avila et al., 1993). In following years, two serological studies have been conducted in San Rafael de Heredia, both of which yielded positive results for T. cruzi in dogs (Montenegro et al., 2002; Lizundia et al., 2014).

The use of indirect or serological diagnostic tests, such as indirect hemagglutination (IHA), enzyme immunoassay (ELISA), or indirect immunofluorescence assay (IFA), is recommended for detecting T. cruzi

\footnotetext{
* Corresponding author.

E-mail address: mabongo27@gmail.com (M.C. Bonilla).
} 


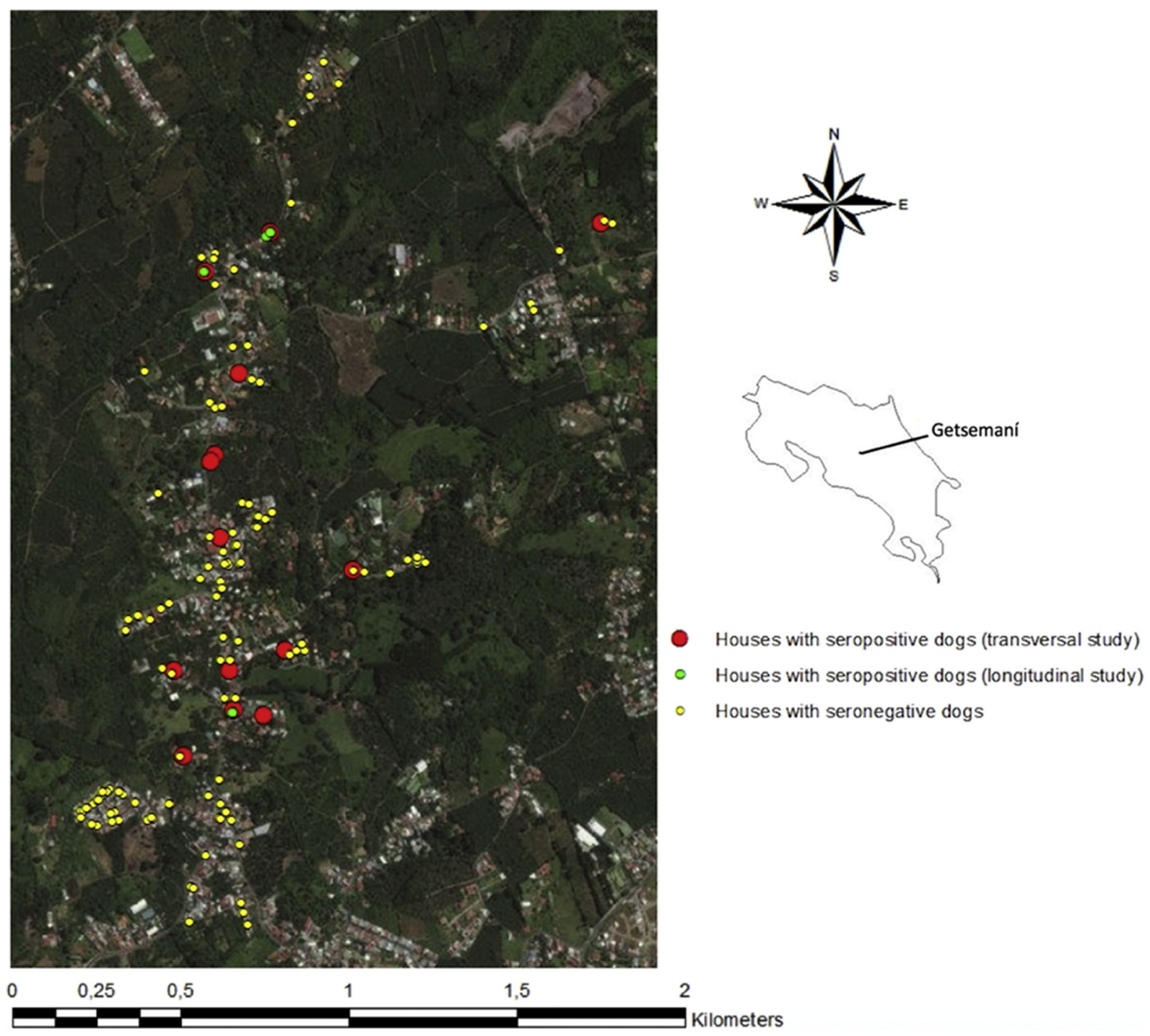

Fig. 1. Distribution of the dwellings studied and T. cruzi-seropositive dogs in the community of Getsemaní 2015-2016.

infection in dogs, since once they have been infected with the parasite they will develop antibodies during the first 7 to 15 days post infection, which can be detected throughout the rest of their lives (Tenney et al., 2014). However, the use of at least two serological techniques is recommended to confirm a positive result (Ribeiro et al., 2012; BautistaLópez et al., 2016). Direct tests can also be used to detect the parasite, including observation of parasitic phases using light microscopy or the molecular polymerase chain reaction (PCR) technique (Telleria and Tibayrenc, 2010; Tanowitz and Weiss, 2017).

The $T$. cruzi parasite has high genetic diversity and has recently been classified in seven evolutionary lineages or Discrete Typing Units (DTU), based on genotypic differences: TcI, TcII, TcIII, TcIV, TcV, TcVI and TcBat (Muñoz-San Martín et al., 2017). However, very few correlations have been observed between the distribution of these evolutionary lineages and the clinical characteristics of the disease. The most abundant and heterogeneous evolutionary lineage is TcI, which has been reported in triatomine vectors as well as in humans and wild and domestic animals, and this genotype has been found in both wild and domestic cycles (Muñoz et al., 2013; Padilla et al., 2017). This lineage has also been found in an opossum, a dog, eleven triatomines and three humans in Costa Rica (Zuriaga et al., 2012).

Very few studies of canine trypanosomiasis have been carried out in Costa Rica and no research has been conducted on T. cruzi infection in dogs from endemic areas over time using serological and molecular diagnosis, nor have the $T$. cruzi evolutionary lineages that are infecting dogs in endemic areas been characterized. This is therefore the first study carried out in a T. cruzi endemic community (Getsemaní) with the objectives of determining the prevalence and occurrence of new cases of $T$. cruzi in canines during a period of one year, confirming if the cycle of infection of the parasite is active in this community, and characterizing the evolutionary lineages present in dogs and vectors in the community.

\section{Methodology}

\subsection{Description of the study area}

The study was carried out in the community of Getsemaní, part of which is in the district of Santa Lucía in Barva and the other in Los Ángeles in San Rafael of Heredia. The community is located in a periurban area to the north of the city of Heredia. It is approximately $1240-1500 \mathrm{~m}$ above sea level, and has an average temperature of $20.1^{\circ} \mathrm{C}$. Annual rainfall is approximately $2374 \mathrm{~mm}$, and the dry season extends from December through April. It is a rocky area due to its proximity to the Barva volcano. The main economic activities in the area are coffee cultivation and animal husbandry (cattle and pigs), and as a result it has large areas of pastures and forests (Moreno Álvarez et al., 1998; Sandoval, 2011; Sandoval and Barrantes, 2012). This 
community was selected because it is considered endemic for Chagas disease, based on the finding of vectors and reports of the disease in humans and animals (Montenegro et al., 2002; Lizundia et al., 2014).

\subsection{Type of study}

A cross-sectional, observational and descriptive study was conducted in 2015 to determine the prevalence and current status of canine trypanosomiasis in Getsemaní. Subsequently, in 2016, a longitudinal, observational and descriptive study was carried out with 55 dogs whose T. cruzi tests had yielded negative results in 2015; they were monitored for one year.

\subsection{Sample type and size}

The transversal study included 175 dwellings with dogs, in which the residents were willing to participate in the project, out of a total of 423 houses in the community of Getsemaní. Blood samples were taken from all dogs present in these dwellings (314), and triatomes were sought for in the dwellings and their surroundings (Fig. 1).

In the longitudinal study, blood was collected from 55 dogs whose $T$. cruzi tests had yielded negative results during the transversal study. These dogs were examined four times during a year, at intervals of approximately four months (January, May, September and December 2016). The sample was divided into two groups. Group 1 consisted of 25 T. cruzi-negative dogs who lived in 12 dwellings where infected triatomines (Triatoma dimidiata) were found in the previous transversal study in their homes (6) and surroundings (6); and Group 2, which consisted of $30 \mathrm{dogs}$, also T. cruzi-negative, that lived in 16 dwellings where triatomines were not found during the previous study in their homes or surroundings, but which were living near the dogs of Group 1.

\subsection{Data collection}

To carry out the study, homeowners gave their informed consent, and were contacted via telephone one week before to coordinate visits for sampling and examination of the dogs. The study was also authorized by the Animal Welfare and Bioethics Commission of the School of Veterinary Medicine of the Universidad Nacional of Costa Rica (No. 03-2014).

A clinical record was filled out during each visit, including information about the homeowner (name, address, geographic coordinates, and a previously assigned house code), information about the dog (name, breed, age, sex, use, management of the dog, travelling information and a previously assigned code), and the results of the clinical examination (temperature, heart rate, respiratory rate, capillary refill time, mucous membrane color, hydration, heart sounds, size and shape of lymph nodes, and attitude), to be able to evaluate possible changes in the canines.

\subsection{Collection of blood samples and bugs}

Dogs were properly held and disinfected when blood samples were taken, always under the supervision of a veterinarian. The samples (approximately $4 \mathrm{ml}$ ) were taken from the cephalic or saphenous veins, $1 \mathrm{ml}$ of blood was placed in tubes without anticoagulant, and $3 \mathrm{ml}$ in tubes with EDTA (sodium salt of ethylenediaminetetraacetic acid). All tubes were labeled with the code previously assigned to the canine and transported at $4{ }^{\circ} \mathrm{C}$ in a cooler to the laboratory, where serum was separated by centrifugation ( $2000 \mathrm{~g}$ for $10 \mathrm{~min}$ ), labeled, and frozen at $-20^{\circ} \mathrm{C}$. The blood samples with EDTA were centrifuged in the same way to take a drop from the leukocyte layer, which was analyzed with a light microscope; the rest of the sample was frozen at $-20^{\circ} \mathrm{C}$ until molecular analysis was carried out.

During the cross-sectional study, a search for triatomines was carried out in the 175 dwellings and their surroundings. A two-person team searched for and collected bugs in all areas of each house with, on average, one man-hour of search time spent. For peridomestic structures, the mean searching effort was also one man-hour. The insects were collected manually, placed in plastic jars, and frozen at $-20{ }^{\circ} \mathrm{C}$ until they were processed using molecular techniques.

\subsection{Microscopic observation}

The drop from the leukocyte layer of the blood sample with EDTA was placed on a glass slide, covered, and observed under a light microscope at a magnification of 10,20 and 40 to determine the presence of trypomastigotes in each sample.

\subsection{Serological analysis}

Sera were analyzed with a commercial IHA test from Wiener Laboratories ("Chagastest HAI", Rosario, Argentina). The IHA test was performed following the protocol recommended by the manufacturer; samples that showed inhibition of the hemagglutination in the 1:16 dilution was considered positive. These sera were subjected again to an IHA test with serial dilutions (from 1:16 to 1: 4096) to determine the final titer (Villegas, 2008).

A culture of T. cruzi epimastigotes in an exponential growth phase in a liver infusion tryptose medium was used for the IFA slides. $25 \mu \mathrm{l}$ $\left(1.3 \times 10^{6}\right.$ parasites $/ \mathrm{ml}$ Locke solution) was placed in each of the wells of the slides, dried at $37^{\circ} \mathrm{C}$ for $15 \mathrm{~min}$, and fixed with pure acetone for $2 \mathrm{~min}$, after which they were kept at $-20^{\circ} \mathrm{C}$ until they were used. The sera were diluted 1:32 in Phosphate Buffered Saline (PBS), and $25 \mu 1$ was placed in each of the wells. A positive control serum and a negative control serum were also included on each slide. The slides were incubated for $30 \mathrm{~min}$ at $37{ }^{\circ} \mathrm{C}$ in a moist chamber and washed twice with PBS for $10 \mathrm{~min}$, after which a conjugate was added (anti-dog IgG with fluorescein; 0855325, MP Biomedicals ${ }^{\circ}$, diluted 1:40). They were then incubated again for $30 \mathrm{~min}$ at $37^{\circ} \mathrm{C}$ in the moist chamber, two additional washings were carried out with PBS and the slides were observed using an immunofluorescence microscope. Sera that showed fluorescence in the 1:32 dilution were considered positive. The positive sera were subjected again to the IFA testing (dilutions of $1: 32$ to $1: 4096$ ) to determine the final titer (Villegas, 2008).

\subsection{Molecular analysis}

DNA extraction from the blood of dogs and from the rectal ampoules of the triatomines was carried out using the DNeasy Blood and Tissue Kit (Qiagen ${ }^{\circledR}$, Chatsworth, CA, USA), following the manufacturer's recommendations. The DNA was then used to amplify a segment of approximately $667 \mathrm{bp}$ of the $18 \mathrm{~S}$ rRNA gene, using nested PCR (Pinto et al., 2015; Aleman et al., 2017). The primers that were used in the first round were SSU4_F (5'-TGCCAGCACCCGCGGTAAT-3') and 18Sq1R (5'-CCACCGACCAAAAGCGGCCCC-3') (Pinto et al., 2015). The primers used in the second round were SSU561F ( $5^{\prime}$-TGGGATAACAA AGGAGCA-3') and SSU561R (5'-CTGAGACTGTAACCTCAAAGC-3') (Noyes et al., 1999).

The PCR reaction was carried out in a final volume of $25 \mu$, adding approximately $1 \mu \mathrm{l}(10 \mathrm{ng})$ of DNA from the sample, $12.5 \mu 1$ DreamTaq ${ }^{\text {TM }}$ PCR Master Mix $2 \times$ (ThermoScientific, USA), $0.5 \mu \mathrm{l}$ each of the two primers in each round $(16 \mu \mathrm{M})$ and $11 \mu \mathrm{l}$ of nuclease-free water (ThermoScientific, USA) (Noyes et al., 1999). A sample isolated from a vector and previously confirmed as positive for $T$. cruzi by sequencing (GenBank MH020170) was used as a positive control; Nuclease-free water (ThermoScientific, USA) was used as a negative control. The nested PCR followed a touchdown protocol, which was used in both rounds (Murphy and O'Brien, 2007; Aleman et al., 2017).

Electrophoresis of all the products of the second round was performed in 1\% agarose gels (Noyes et al., 1999), using GelRed for DNA staining, and was carried out in an electrophoresis chamber at $100 \mathrm{~V}$ for 
Table 1

Serological results of the six dogs that displayed seroconversion during the longitudinal study in Getsemaní community.

\begin{tabular}{|c|c|c|c|c|c|c|c|c|c|c|c|}
\hline \multirow[t]{2}{*}{ House } & \multirow[t]{2}{*}{ Dog } & \multicolumn{2}{|c|}{ September $2015^{\mathrm{a}}$} & \multicolumn{2}{|c|}{ January 2016} & \multicolumn{2}{|l|}{ May 2016} & \multicolumn{2}{|c|}{ September 2016} & \multicolumn{2}{|c|}{ December 2016} \\
\hline & & IHA & IFA & IHA & IFA & IHA & IFA & IHA & IFA & IHA & IFA \\
\hline 4 & 1 & - & - & - & - & $+(1: 512)$ & $+(1: 1024)$ & $+(1: 512)$ & $+(1: 512)$ & $+(1: 512)$ & $+(1: 1024)$ \\
\hline 4 & $2^{\mathrm{b}}$ & - & - & - & - & $+(1: 128)$ & $+(1: 256)$ & $+(1: 512)$ & $+(1: 512)$ & $+(1: 1024)$ & $+(1: 512)$ \\
\hline 5 & 3 & - & - & $+(1: 512)$ & $+(1: 512)$ & $+(1: 1024)$ & $+(1: 512)$ & $+(1: 512)$ & $+(1: 512)$ & $+(1: 512)$ & $+(1: 512)$ \\
\hline 7 & 4 & - & - & $+(1: 64)$ & $+(1: 256)$ & $+(1: 128)$ & $+(1: 256)$ & $+(1: 64)$ & $+(1: 128)$ & $+(1: 64)$ & $+(1: 256)$ \\
\hline 7 & 5 & - & - & $+(1: 128)$ & $+(1: 128)$ & $+(1: 64)$ & $+(1: 128)$ & NA & $\mathrm{NA}$ & NA & NA \\
\hline 22 & 6 & - & - & - & - & $+(1: 1024)$ & $+(1: 1024)$ & $+(1: 1024)$ & $+(1: 512)$ & $+(1: 1024)$ & $+(1: 256)$ \\
\hline
\end{tabular}

${ }^{\text {a }}$ Results of the transversal study. IHA: indirect hemagglutination, IFA: indirect immunofluorescence. NA: Not analyzed, due to death.

b PCR positive in the May 2016 evaluation.

30 to $40 \mathrm{~min}$. The GenRuler 100 bp DNA Ladder Plus (Fermentas ${ }^{\circledast}$ ) was used as a molecular weight marker. Bands that showed a molecular weight of approximately $667 \mathrm{bp}$ (Aleman et al., 2017) were considered positive for T. cruzi and sent to Macrogen Inc. (Seoul, South Korea) to be purified and sequenced.

The partial sequences obtained were edited using the BioEdit Sequence Alignment Editor ${ }^{\circledR}$ program (Hall, 1999); they were compared with the database of the National Center for Biotechnology Information (NCBI) using the BLASTn algorithm, and the alignments were made using the MUSCLE program (Edgar, 2004). The partial sequences obtained and edited were deposited in GenBank.

A phylogenetic tree was constructed using the MEGA 7 program (Molecular Evolutionary Genetics Analysis) with all partial sequences edited (Kumar et al., 2016). The Kimura 2-parameter sequence evolution model (Kimura, 1980) with a gamma distribution was used. In addition, the analysis used the Neighbor-Joining method, and 1000 resamplings (bootstrapping) were used as a statistical test.

The partial sequences of Trypanosoma erneyi (JN040989) and Trypanosoma dionisii (FJ001662) deposited in GenBank were used as external groups to construct the phylogenetic tree. The sequences used to determine the T. cruzi evolution lineage were: TcI (FJ001631), TcII (AF301912), TcIII (AF303660), TcIV (AY491761), TcV (AF228685), TcVI (AF245383), and TcBat (KT829450).

\subsection{Spatial analysis}

Using spatial methods (geographic positioning systems, geographic information systems and remote sensing systems) the distribution of the seropositive dogs to T. cruzi in Getsemaní was determined. Briefly, geographical coordinates of dwellings were taken, and the results of serological assays recorded. Subsequently, this information was transferred to a software of geographic information systems (ArcGis), and a thematic map elaborated.

\section{Results}

Of the 314 dogs examined in the cross-sectional study, $20(6.4 \%)$ yielded positive results in serological tests; they showed antibody titers ranging from $1: 64$ to $1: 128$ in IHA and $1: 32$ to $1: 512$ in IFA. Seropositive canines were found in 14 dwellings throughout the community (Fig. 1). In addition, in eight (57.1\%) of the 14 dwellings with seropositive dogs, triatomines ( $T$. dimidiata) were found inside the houses or in their surroundings. Trypomastigotes were only found by light microscope in the blood sample of one canine (0.3\%), which also yielded positive results in PCR. The blood sample came from a 2-month old puppy, whose serum sample yielded negative results in both serological tests; therefore, it was classified as a case of asymptomatic acute trypanosomiasis.

A total of $21(12.0 \%)$ dwellings were found infested with triatomines, that were located mainly in peridomestic places $(n=12)$, like wooden accumulations and dog cages. In seven dwellings the insects were found intra-domicile, in bedrooms and in one mechanical workshop, and in two houses the insects were found intra- and peridomiciliar. All 101 triatomines found in Getsemaní were classified as Triatoma dimidiata (Lent \& Wygodzinsky, 1979), and $82.2 \%(n=83)$ were found positive by PCR to T. cruzi. The infected insects were found in 12 homes (Argüello, 2018).

In the longitudinal study, the presence of trypomastigotes in blood samples was not observed using light microscopy in either of the two groups in any of the four periods (January, May, September and December 2016) during which the dogs were studied. Of the 25 canines analyzed in Group 1 in the longitudinal study (T. cruzi-negative canines that lived in dwellings where triatomines were found), three dogs were found to be seropositive in the first visit (January 2016), and three other dogs were found to be seropositive in the second visit (May 2016) - an incidence rate of $24 \%(6 / 25)$ was determined in Group 1 . The six seropositive canines were detected in a total of four houses (Fig. 1): two of them with only one seropositive dog each, and two others with two seropositive dogs each. Four of these six dogs did not have a defined breed, one was an American Staffordshire Terrier, and another was a Cocker Spaniel. In addition, four were females and two males, and five were young adults between 1 and 6 years old, while the other dog was geriatric, 14 years old.

Throughout the study, the six dogs that displayed seroconversion showed normal values for temperature, heart rate, respiratory rate, capillary filling time, and pink mucous membranes; all of them were hydrated, alert, and docile. One dog (Dog 2) had enlarged popliteal lymph nodes in two of the exams (May and September of 2016), and another (Dog 4) had abnormal heart sounds (a heart murmur) throughout the study. All six dogs were housed in homes as pets, were not used for hunting and slept outside the house at night. In addition, all the houses had a patio or large green areas and the dogs did not leave their home areas.

These dogs remained seropositive through the end of the study, with antibody titers ranging from 1:64 to 1:1024 in IHA and 1:128 to 1:1024 in IFA (Table 1). It was not possible to study one dog throughout the study, since it died of poisoning. The other 19 dogs in Group 1 remained negative throughout the follow-up year, as did the 30 canines in Group 2 (T. cruzi-negative dogs living in houses where no triatomines were found previously).

Of the 55 dogs analyzed during 2016 in the community of Getsemaní, only one (Dog 2), that belonged to Group 1, was found to be T. cruzi-positive by PCR (Table 1 and Fig. 2) on the second sample taken (May 2016), and also showed seroconversion and an increase in the size of its popliteal lymph nodes. In the third exam (September 2016), Dog 2 continued to show an increase in the size of its popliteal lymph nodes, but PCR results were negative, while antibodies were detected through the end of the study. Its popliteal lymph nodes were of normal size in the fourth exam (December 2016).

Triatoma dimidiata were found in all the houses in which dogs seroconverted during the longitudinal study (houses 4, 5, 7 and 22). The PCR analysis determined these triatomines positive for T. cruzi (Fig. 2). 


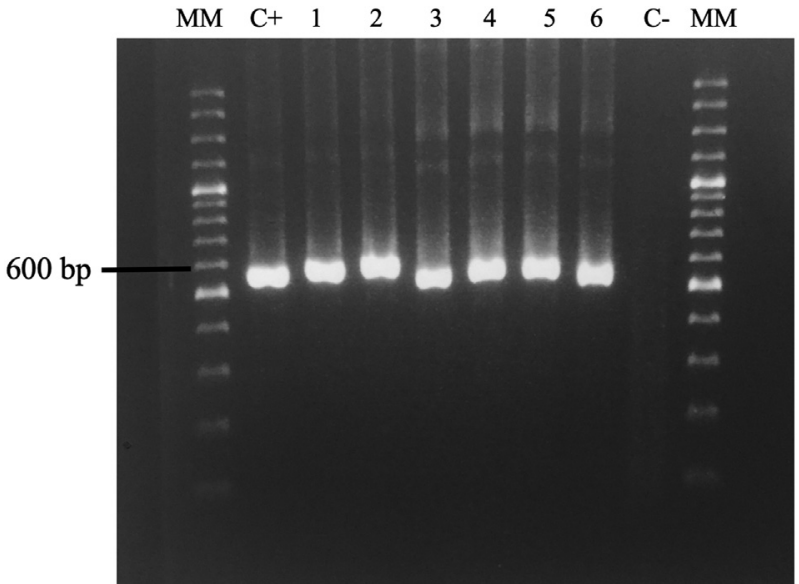

Fig. 2. Electrophoretic analysis of T. cruzi-positive canine and triatomine samples using PCR. MM: Molecular weight marker (GenRuler 100 bp DNA Ladder Plus, Fermentas ${ }^{\circledast}$ ), C+: Positive control, triatomine (GenBank MH020170) 1: Puppy, cross-sectional study (GenBank MH045194), 2: Dog 2, longitudinal study (GenBank MH045195), 3: Triatomine, House 4 (GenBank MH045196), 4: Triatomine, House 5 (GenBank MH045197), 5: Triatomine House 7 (GenBank MH045198), 6: Triatomine House 22 (GenBank MH045199), C-: Negative control.

The amplified PCR-positive canine blood samples (puppy from the transversal study and Dog 2 from the longitudinal study), and PCR positive triatomines from houses $4,5,7$ and 22 (in which dogs seroconverted during the longitudinal study), were sent to Macrogen Inc. to be purified and sequenced. The partial sequences obtained showed a $100 \%$ (638/638 bp) nucleotide identity among them, and 100\% (638/ $638 \mathrm{bp}$ ) nucleotide identity with the isolated sequence of a rodent in Texas, USA (LT220278). In addition, they showed a 98\% (586/589) nucleotide identity with the sequence obtained from a bat in Brazil (FJ001631), which belonged to the TcI lineage.

The phylogenetic relationships between the sequences obtained from dogs and bugs in Getsemaní community, with the sequences obtained from a US rodent (LT220278) and a bat from Brazil (Lineage TcI, FJ001631) are presented in Fig. 3, the sequences of Getsemaní were clearly determined belonging to the TcI lineage of $T$. cruzi, with a bootstrap value of $97 \%$ and deposited in Gen Bank under accession numbers MH045194.1 to MH045199.1).

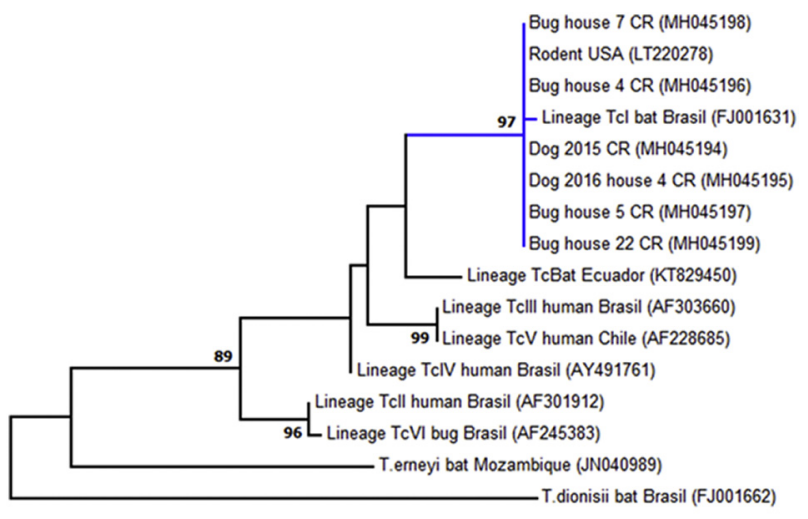

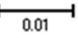

Fig. 3. Phylogenetic tree based on the $638 \mathrm{bp}$ sequences of the $18 \mathrm{~S}$ rRNA gene from the samples of dogs and bugs infected with $T$. cruzi from the community of Getsemaní.

\section{Discussion}

The finding of 20 serologically positive dogs in the transversal study and the detection of seroconversions in dogs in the longitudinal study confirmed that the T. cruzi infection cycle continues to be active in the community of Getsemaní (Nieto et al., 2009), and that dogs have had contact with the parasite. The T. cruzi seroprevalence of $6.4 \%(20 / 314)$ found in dogs in the transversal study and the finding of seropositive dogs to T. cruzi in 14 dwellings makes it possible to estimate the risk of infection of the humans living in this endemic area. These results can be used to increase awareness of the importance to report canines' infections as part of epidemiological surveillance programs to control human cases (Abad-Franch et al., 2010; Barbabosa-Pliego et al., 2011; Greene, 2012; Castillo-Neyra et al., 2015).

Serological techniques are considered the most appropriate tests for the diagnosis of Chagas disease, since antibodies can be detected around 7 to 15 days after infection and persist for the rest of the lives in infected individuals, or for as long as these individuals remain infected (in case of humans that can be treated) (Nieto et al., 2009; Rodrigues and Borgues-Pereira, 2010; Tenney et al., 2014).

The use of light microscopy to detect parasitic forms of T. cruzi is recommended in cases in which there are clinical or epidemiological suspicions of an acute phase, since a greater amount of trypomastigotes circulating in blood can be observed during the first weeks after infection (Vega and Náquira, 2006; Abras et al., 2017). The puppy found to be positive using light microscopy and PCR in the transversal study, in which antibodies against the agent or clinical signs were not found, indicates that the puppy had been recently infected and was in an acute phase of infection.

The finding of a PCR-positive dog in May 2016 in the longitudinal study with enlarged popliteal lymph nodes and which was found in the following examination to be PCR-negative but serologically positive, indicates that the dog was possibly ending the acute phase in May, and by the time of the next examination had entered to the indeterminate phase. This phase is characterized by a reduction of parasitemia due to intracellular infection of cardiac cells, where the parasite continues replicating itself for many years without causing evident clinical signs (Vega and Náquira, 2006; Abras et al., 2017).

The same genetic variant of the T. cruzi parasite, the TcI lineage, was observed in both vectors and dogs in Getsemaní community, which agrees with previous studies that reports this lineage to be the most common in Central America (Zuriaga et al., 2012; Dorn et al., 2017). The finding of TcI in sympatric vectors and in dogs needs further studies in order to identify genotypic differences using more appropriate gene markers and assays with better sensitivity that could contribute to elucidate population dynamics (Izeta-Alberdi et al., 2016).

It was found that dwellings with vectors and seropositive canines were distributed throughout Getsemaní community, and that the distribution of triatomines and seropositive canines were coinciding with each other. Furthermore, in the longitudinal study dogs seroconverted only in dwellings in which triatomines had previously been found, showing that this represents a risk for infection for humans and domestic animals (Eloy and Lucheis, 2009).

In the longitudinal study, all canines seroconverted during the first months of the year, which is the dry season in Getsemaní community (Moreno Álvarez et al., 1998; Sandoval, 2011; Sandoval and Barrantes, 2012). This is consistent with findings from studies in Mexico that reported that populations of $T$. dimidiata were more abundant during the dry season, which has been associated with greater colonization of dwellings by these insects (Dumonteil et al., 2002). However, further studies should be carried out to confirm that these two factors - the vector-host relationship and the dry season - are risk factors for T. cruzi infection in the dogs in Getsemaní community.

The treatment of infected canines is controversial because no veterinary drugs are registered against $T$. cruzi and experimental studies have shown that Nifurtimox and Benznidazole cause multiple side 
effects (vomiting, nausea, convulsions), due to toxicity in dogs (Greene, 2012). Furthermore, only an initially decrease of the parasitic load was recorded with Benznidazole (Santos et al., 2016). Infected canines that present cardiac symptomatology need to be treated with supportive therapy (medication for cardiac function, bronchodilators, and diuretics among others), nevertheless, the prognosis in these animals is reserved, since they usually develop the chronic phase and die suddenly (Greene, 2012).

For these reasons it is important to educate the population in endemic areas to treat their dogs in a prophylactic way, using systemic insecticides (Fluranaler or others) to avoid triatomines feeding on infected dogs, as well as to avoid infection of negative dogs by infected triatomines, and to interrupt the transmission cycle (Abad-Franch et al., 2010; Greene, 2012). Finally, since the congenital transmission of $T$. cruzi has a high rate, an important recommendation should be also to avoid reproduction of infected females (Greene, 2012; Berrizbeitia et al., 2013; Rodrigues, 2015). The population of Getsemaní is therefore advised to remain alert to the appearance of vectors in their homes, to implement the entomological surveillance protocols that have been established in the country, and to follow the prophylactic measures recommended for dogs.

In addition to the presence of the hematophagous vector ( $T$. dimidiata) in dwellings, other risk factors include the ways in which the dwellings are constructed, their proximity to coffee plantations or vacant lots, and the accumulation of materials in or around the dwellings (Government of Costa Rica, 2012). These factors are present in many of the dwellings in Getsemaní, given that the main activities in the area are agriculture (Moreno Álvarez et al., 1998; Sandoval, 2011; Sandoval and Barrantes, 2012). Changes in the environment of houses infested with triatomines have been successful and turn out to be also a good way of permanent control, less expensive, more sustainable and realistic, than using fumigation with insecticides (Zeledón et al., 2008). For example, eliminating the wooden accumulations, avoiding the use of lights in the peridomiciliary area, not allowing pets to sleep outside the house and preventing the pests of synanthropic animals.

\section{Conclusions}

The appearance of new serologically $T$. cruzi-positive dogs in this study indicates that the cycle of infection of the parasite is active in the community of Getsemaní. It was shown that cases of canine trypanosomiasis were higher in the group of canines that were living in dwellings with infected vectors, which could also represent a risk of infection for people living in these dwellings. It is recommended that residents be made aware of the need to eliminate vectors in their homes to reduce the incidence of infections among their dogs and to instruct them about the need to treat their infected dogs to interrupt the transmission cycle. It is also recommended that the residents of Getsemaní and other endemic communities of Costa Rica be educated and informed about the contents of the Standard for the Comprehensive Care of Chagas Disease (Government of Costa Rica, 2012).

\section{Acknowledgements}

The authors wish to thank all the owners of dogs in the Getsemaní community who were willing to participate in the present study, as well as the laboratory assistants and students of the School of Veterinary Medicine of the Universidad Nacional de Costa Rica who collaborated in the different stages of the study. We also thank the members of the Health Area of San Rafael de Heredia and INCIENSA for their support in carrying out this research. This project was financed with FIDA funds from the Fundación para el Desarrollo Académico de la Universidad Nacional (FUNDAUNA), and by the Vicerectoría de Investigación of the Universidad Nacional.

\section{Ethical statement}

The study from the manuscript entitled "Canine trypanosomiasis in an endemic Costa Rican community: demonstration of the active infection cycle" which was sent to considered as an original article in the Journal Veterinary Parasitology: Regional Studies and Reports, was authorized by the Animal Welfare and Bioethics Commission of the School of Veterinary Medicine of the Universidad Nacional of Costa Rica (No. 03-2014).

This research was conducted under all the ethical and animal welfare arrangements that involve canines in the field.

\section{References}

Government of Costa Rica, 2012. Norma de atención integral de la enfermedad de Chagas. In: [Standard for the Comprehensive Care of Chagas Disease, 2012]. Executive Decree $\mathrm{N}^{\circ}$ 37269-S. Presidency of the Republic and Ministry of Health. Government of Costa Rica.

Abad-Franch, F., Santos, W.S., Schofield, C.J., 2010. Research needs for Chagas disease prevention. Acta Trop. 115 (1), 44-54.

Abras, A., Muñoz, C., Ballart, C., Berenguer, P., Llovet, T., Herrero, M., Tebar, S., Pinazo, M.J., Posada, E., Martí, C., Fumadó, V., Bosch, J., Coll, O., Juncosa, T., Ginovart, G., Armengol, J., Gascón, J., Portús, M., Gállego, M., 2017. Towards a new strategy for the diagnosis of congenital Trypanosoma cruzi infection. J. Clin. Microbiol. 55 (5), 1396-1407.

Aleman, A., Guerra, T., Maikis, T.J., Milholland, M.T., Castro-Arellano, I., Forstner, M.R.J., Hahn, D., 2017. The prevalence of Trypanosoma cruzi, the causal agent of Chagas disease, in Texas rodent populations. Ecohealth. 14 (1), 130-143.

Argüello, M., 2018. Epidemiología de la infestación de Triatoma dimidiata (Hemiptera: Reduviidae), vector de la enfermedad de Chagas, en la comunidad de Getsemaní de Heredia. In: Tesis para optar por el grado académico de Magister Scientiae en Enfermedades Tropicales (Epidemiology of the infestation of Triatoma dimidiata (Hemiptera: Reduviidae), vector of Chagas disease, in the community of Getsemani in Heredia. Thesis for the degree of Magister Scientiae in Tropical Diseases.). Universidad Nacional, Heredia, Costa Rica.

Barbabosa-Pliego, A., Campos, P., Olivares, D., Aparicio-Burgos, J.E., Montes de OcaJiménez, R., Martínez-Castañeda, J.S., Ochoa-García, L., Guzmán-Bracho, C., Estrada Franco, J.G., Garg, N.J., Vazquez, J.C., 2011. Prevalence of Trypanosoma cruzi in dogs (Canis familiaris) and triatomines during 2008 in a sanitary region of the State of Mexico, Mexico. Vector Borne Zoonotic Dis. 11 (2), 151-156.

Bautista-López, N.L., Ndao, M., Vázquez, F., Nara, T., Annoura, T., Hardie, D.B., Borchers, C.H., Jardim, A., 2017. Characterization and diagnostic application of Trypanosoma cruzi trypomastigote excreted-secreted antigens shed in extracellular vesicles released from infected mammalian cells. J. Clin. Microbiol. 55 (3), 744-758.

Berrizbeitia, M., Concepción, J.L., Carzola, V., Rodríguez, J., Cáceres, A., Quiñones, W., 2013. Seroprevalence of T. cruzi infection in Canis familiaris, state of Sucre, Venezuela. Biomédica 33 (2), 214-225.

Berrocal-Avila, A., Morales-Acuña, J.A., Cordero, V., Villalobos, C., 1993. Miocarditis aguda chagásica en caninos de Costa Rica. Acute myocarditis due to Trypanosoma cruzi in dogs in Costa Rica. Ciencias Veterinarias Costa Rica. 15 (1), 51-59.

Castillo-Neyra, R., Chou Chu, L., Quispe-Machaca, V., Ancca-Juarez, J., Chavez Malaga, F.S., Bastos Mazuelos, M., Naquira, C., Bern, C., Gilman, R.H., Levy, M.Z., 2015. The potential of canine sentinels for reemerging Trypanosoma cruzi transmission. Prev. Vet. Med. 120 (3), 349-356.

Dorn, P.L., McClure, A.G., Gallaspy, M.D., Waleckx, E., Woods, A.S., Monroy, M.C., Stevens, L., 2017. The diversity of the Chagas parasite, Trypanosoma cruzi, infecting the main Central American vector, Triatoma dimidiata, from Mexico to Colombia. PLoS Negl. Trop. Dis. 11 (9), e0005878.

Dumonteil, E., Gourbière, S., Barrera-Pérez, M., Rodriguez-Félix, E., Ruiz-Piña, H., BañosLopez, O., Ramirez-Sierra, M.J., Menu, F., Rabinovich, J.E., 2002. Geographic distribution of Triatoma dimidiata and transmission dynamics of Trypanosoma cruzi in the Yucatan peninsula of Mexico. Am. J. Trop. Med. Hyg. 67 (2), 176-183.

Edgar, R.C., 2004. MUSCLE: multiple sequence alignment with high accuracy and high throughput. Nucleic Acids Res. 32 (5), 1792-1797.

Eloy, L.J., Lucheis, S.B., 2009. Canine trypanosomiasis: etiology of infection and implications for public health. J. Venom. Anim. Toxins Incl. Trop. Dis. 15 (4), 589-611.

Galvao, C., Justi, S.A., 2015. An overview on the ecology of Triatominae (Hemiptera: Reduviidae). Acta Trop. 151, 116-125.

Greene, C., 2012. Infectious Diseases of the Dog and Cat, 4 ed. Elsevier, United States.

Hall, T.A., 1999. BioEdit: a user-friendly biological sequence alignment editor and analysis program for Windows 95/98/NT. Nucleic Acids Symp. Ser. 41, 95-98.

Izeta-Alberdi, A., Ibarra-Cerdeña, C.N., Moo-Llanes, D.A., Ramsey, J.A., 2016. 2016 Geographical, landscape and host associations of Trypanosoma cruzi DTUs and lineages. Parasit. Vectors 9, 631, https://doi.org/10.1186/s13071-016-1918-2.

Kimura, M., 1980. A simple method for estimating evolutionary rate of base substitutions through comparative studies of nucleotide sequences. J. Mol. Evol. 16, 111-120.

Kumar, S., Stecher, G., Tamura, K., 2016. MEGA7: molecular evolutionary genetics analysis version 7.0 for bigger datasets. Mol. Biol. Evol. 33 (7), 1870-1874.

Lent, H., Wygodzinsky, P., 1979. Revision of the Triatominae (Hemiptera, Reduviidae), and their significance as vectors of Chagas' disease. Bulletin of the American Museum of Natural History Bulletin of the AMNH 163, 3. http://hdl.handle.net/2246/1282. 
Lizundia, R., Picado, A., Cordero, M., Calderon, A., Deborggraeve, S., Montenegro, V.M., Urbina, A., 2014. Molecular and serological rapid tests as markers of Trypanosoma cruzi infection in dogs in Costa Rica. Trop. Parasitol. 4 (2), 111.

Ministry of Agriculture and Livestock (Ministerio de Agricultura y Ganaderia, MAG), 2008. Listado de enfermedades animales de declaración obligatoria. Decreto No 34669-MAG. Presidencia de la República y Ministerio de Agricultura y Ganadería, Costa Rica (List of animal diseases which must be reported). Decree No. 34669-MAG. Presidency of the Republic and Ministry of Agriculture and Livestock, Costa Rica.

Montenegro, V.M., Jimenez, M., Dias, J.C., Zeledon, R., 2002. Chagas disease in dogs from endemic areas of Costa Rica. Mem. Inst. Oswaldo Cruz 97, 491-494.

Moreno Álvarez, R., Carballo Hernández, M.A., Vargas Lobo, F., 1998. Mejoramiento ambiental de la parte alta de la cuenca del río Segundo para la comunidad de Getsemaní de San Rafael de Heredia. Proyecto Integral. Práctica de formulación, administración y evaluación de proyectos I y II (Environmental improvement of the upper part of the Segundo River basin for the Getsemani community of San Rafael de Heredia. Comprehensive Project. Formulation, administration and evaluation practices of projects I and II). Facultad de Ciencias Sociales. Escuela de Planificación económica y social. Universidad Nacional, Costa Rica.

Muñoz, C., Solari, A., APT, W., Zulantay, I., 2013. Caracterización de las unidades discretas de tipificación de Trypanosoma cruzi según sus marcadores moleculares (Characterization of Discrete Typing Units of Trypanosoma cruzi based on molecular markers.). Ibero-Latinoamericana de Parasitología Chile. pp. 5.

Muñoz-San Martín, C., Apt, W., Zulantay, I., 2017. Real-time PCR strategy for the identification of Trypanosoma cruzi discrete typing units directly in chronically infected human blood. Infect. Genet. Evol. 49, 300-308.

Murphy, W.J., O'Brien, S.J., 2007. Designing and optimizing comparative anchor primers for comparative gene mapping and phylogenetic inference. Nat. Protoc. 2 (11), 3022-3030.

Nieto, P.D., Boughton, R., Dorn, P.L., Steurer, F., Raychaudhuri, S., Esfandiari, J., Gonçalves, E., Diaz, J., Malone, J.B., 2009. Comparison of two immunochromatographic assays and the indirect immunofluorscence antibody test for diagnosis of Trypanosoma cruzi infection in dogs in south central Louisiana. Vet. Parasitol. 165 (3), 241-247.

Noyes, H.A., Stevens, J.R., Teixeira, M., Phelan, J., Holz, P., 1999. A nested PCR for the ssrRNA gene detects Trypanosoma binneyi in the platypus and Trypanosoma sp. in wombats and kangaroos in Australia. Int. J. Parasitol. 29 (2), 331-339.

Padilla, C.P., Alvarado, U., Ventura, G., Luna-Caipo, D., Suárez, M., Tuñoque, J.R. Ruelas-Llerena, N., Fachin, L.A., Huiza, A., Gonzales, L., Carranza, J.C., Vallejo, G.A., Cáceres, A.G., 2017. Detección de unidades discretas de tipificación de Trypanosoma cruzi en triatominos recolectados en diferentes regiones naturales de Perú (Detection of discrete typing units of Trypanosoma cruzi in triatomines collected in different natural regions of Peru.). Biomédica 37, 167-179.

Pinto, C.M., Ocaña-Mayorga, S., Tapia, E.E., Lobos, S.E., Zurita, A.P., Aguirre-Villacís, F., MacDonald, A., Villacís, A.G., Lima, L., Teixeira, M.M.G., Grijalva, M.J., Perkins, S.L., 2015. Bats, trypanosomes, and triatomines in Ecuador: new insights into the diversity, transmission, and origins of Trypanosoma cruzi and Chagas disease. PLoS One 10 (10), 1-13.

Ribeiro, A.L., Nunes, M.P., Teixeira, M.M., Rocha, M.O., 2012. Diagnosis and management of Chagas disease and cardiomyopathy. Nat. Rev. Cardiol. 9 (10), 576-589.

Rodrigues, J., 2015. The main sceneries of Chagas disease transmission. The vectors, blood and oral transmissions - a comprehensive review. Mem. Inst. Oswaldo Cruz 110 (3), 277-282.

Rodrigues, J., Borgues-Pereira, J., 2010. Chagas disease: 100 years after its discovery. A systemic review. Acta Trop. 115, 3-5.

Sandoval, L., 2011. Inicio de la época reproductiva y tiempo de defensa del territorio en machos de Colinus leucopogon (Galliformes: Odontophoridae) (Beginning of the reproductive period and time of defense of the territory in males of Colinus leucopogon (Galliformes: Odontophoridae)). Rev. Biol. Trop. 59 (1), 363-372.

Sandoval, L., Barrantes, G., 2012. Characteristics of male spot-bellied bobwhite (Colinus leucopogon) song during territory establishment. J. Ornithol. 153 (2), 547-554.

Santos, F.M., Mazzeti, A.L., Caldas, S., Goncalves, K.R., Lima, W.G., Torres, R.M., Bahia, M.T., 2016. Chagas cardiomyopathy: the potential effect of benznidazole treatment on diastolic dysfunction and cardiac damage in dogs chronically infected with Trypanosoma cruzi. Acta Trop. 161, 44-54.

Tanowitz, H.B., Weiss, L.M., 2017. A new development in Trypanosoma cruzi diagnosis. J. Clin. Microbiol. 55 (3), 690-692.

Telleria, J., Tibayrenc, M., 2010. American Trypanosomiasis: Chagas Disease One Hundred Years of Research. Elsevier.

Tenney, T.D., Curtis-Robles, R., Snowden, K.F., Hamer, S.A., 2014. Shelter dogs as sentinels for Trypanosoma cruzi transmission across Texas. Emerg. Infect. Dis. 20 (8), 1323.

Vega, S., Náquira, C., 2006. Manual de procedimientos de laboratorio para el diagnóstico de la Tripanosomiasis americana (Enfermedad De Chagas) (Manual of laboratory procedures for the diagnosis of American Trypanosomiasis (Chagas Disease)). Inst. Nac. Salud, Lima, Perú.

Villegas, A., 2008. Seroprevalencia de la infección por Trypanosoma cruzi en perros de dos zonas rurales con altos y bajos índices de infestación por Triatoma dimidiata. Tesis para optar por el grado académico de Licenciatura en Medicina Veterinaria (Seroprevalence of Trypanosoma cruzi infection in dogs from two rural areas with high and low rates of infestation by Triatoma dimidiata). Thesis for the degree of Veterinary Medicine.). Universidad Nacional, Heredia, Costa Rica.

Zeledón, R., Rojas, J.C., Urbina, A., Cordero, M., Gamboa, S.H., Lorosa, E.S., Alfaro, S., 2008. Ecological control of Triatoma dimidiata (Latreille, 1811): five years after a Costa Rican pilot project. Mem. Inst. Oswaldo Cruz 103 (6), 619-621.

Zeledón, R., Hanson, P., Zumbado, M., 2016. Guía de artrópodos de importancia médica y veterinaria (Guide to Arthropods of medical and veterinary importance). Editorial Universidad Estatal a Distancia, San José, Costa Rica.

Zuriaga, M.Á., Blandón-Naranjo, M., Valerio-Campos, I., Salas, R., Zeledón, R., Bargues, M.D., 2012. Molecular characterization of Trypanosoma cruzi and infection rate of the vector Triatoma dimidiata in Costa Rica. Parasitol. Res. 111 (4), 1615-1620. 